\title{
Acessibilidade como Condição de Acesso, Participação, Desenvolvimento e Aprendizagem de Alunos com Deficiência
}

\author{
Graciele Marjana Kraemer \\ Universidade do Vale do Rio dos Sinos, RS, Brasil.
}

\author{
Adriana da Silva Thoma \\ Universidade Federal do Rio Grande do Sul, RS, Brasil.
}

\begin{abstract}
Resumo: Na racionalidade da governamentalidade biopolítica, a inclusão escolar das pessoas com deficiência constitui-se como estratégia necessária para um bom governo da população. Nesse cenário, perguntamos: como a acessibilidade tem se constituído como condição para o acesso, a participação, o desenvolvimento e a aprendizagem de alunos com deficiência? Para responder essa questão, analisamos documentos - leis e políticas - voltados à inclusão de pessoas com deficiência produzidos a partir dos anos 2000, dentre eles: a Lei no 10.098 , de 19 de dezembro de 2000; o Plano Nacional dos Direitos da Pessoa com Deficiência - Viver sem Limite, de 2013; e a Lei no 13.146 , de 6 de julho de 2015. Como ferramenta teórico-metodológica, utilizamos a noção de governamentalidade biopolítica, na esteira do pensamento de Michel Foucault. As análises buscam mostrar que a acessibilidade se constitui como uma estratégia potencializadora da inclusão escolar e como condição para promover práticas que efetivem e promovam o acesso, a participação, o desenvolvimento e a aprendizagem de alunos com deficiência na escola comum.
\end{abstract}

Palavras-chave: Inclusão, Acessibilidade, Aprendizagem.

\section{Accessibility as a Condition for Access, Participation, Development and Learning of Students with Disabilities}

\begin{abstract}
In the rationality of the biopolitical governmentality, school inclusion of people with disabilities has become a strategy for a good government of the population. In this scenario, we have asked the following question: how has accessibility become a condition for access, participation, development and learning of students with disabilities? In order to answer this question, we have analyzed some documents - acts and policies - intended for the inclusion of people with disabilities dating back to the year 2000, such as Act nr. 10098, from December 19, 2000; the National Plan for the Rights of People with Disabilities - Living with no Limits, from 2013; and Act nr. 13146, from July 6, 2015. As a theoretical-methodological tool, we have used the notion of biopolitical governmentality, in line with Michel Foucault's thought. The analyses have shown accessibility as both a strategy that potentiates the school inclusion and a condition to promote practices that effect and promote access, participation, development and learning of students with disabilities in the regular school.
\end{abstract}

Keywords: Inclusion, Accessibility, Learning. 


\title{
Accesibilidad como Condición de Acceso, Participación, Desarrollo y Aprendizaje de Alumnos com Discapacidad
}

\begin{abstract}
Resumen: En la racionalidad de la gubernamentalidad biopolítica, la inclusión escolar de las personas con discapacidad se constituye como estrategia necesaria para un buen gobierno de la población. En este escenario, preguntamos: ¿Cómo la accesibilidad se ha constituido como condición para el acceso, participación, desarrollo y aprendizaje de alumnos con discapacidad? Para responder a esta cuestión, analizamos documentos - leyes y políticas -orientados a la inclusión de personas con discapacidad producidos a partir del año 2000, entre ellos: la Ley $\mathrm{n}^{\circ}$ 10.098, del 19 de diciembre del 2000; el Plan Nacional de los Derechos de Personas con Discapacidad - Vivir sin límite, 2003; y la Ley n¹3.146, del 6 de julio de 2015. Como herramienta teórica-metodológica, utilizamos la noción de gubernamentalidad biopolítica, con base en el pensamiento de Michael Foucault. Los análisis buscan mostrar que la accesibilidad se constituye como una estrategia potencializadora de la inclusión escolar y también como condición para promover prácticas que hagan efectivo y promuevan el acceso, la participación, el desarrollo y el aprendizaje de alumnos con discapacidad en la escuela común.
\end{abstract}

Palabras clave: Inclusión, Accesibilidad, Aprendizaje.

Este artigo é parte de discussões que temos realizado na pesquisa Inclusão, Subjetivação e Governo das Diferenças na Educação (THOMA, 2016) ${ }^{1}$ desenvolvida no âmbito da Universidade Federal do Rio Grande do Sul (UFRGS) pelo Grupo de Pesquisa SINAIS - Sujeitos, Inclusão, Narrativas, Alteridade, Identidades e Subjetividades e parte do interesse do Conselho Federal de Psicologia (CFP) em investir nas formas de acessibilidade da Revista Psicologia: Ciência e Profissão (PCP). Para discutir princípios e diretrizes de acessibilidade aos sujeitos com deficiência e tratar sobre possibilidades de tornar a Revista acessível a todos, o CFP realizou uma reunião no dia 18 de dezembro de 2017, que contou com a presença de diferentes profissionais com e sem deficiência, do campo da Psicologia e da Educação e, como forma de dar continuidade a esse debate, a Revista propôs a publicação de um número sobre o tema. Assim, nosso objetivo aqui, ao tratar sobre a acessibilidade como condição de acesso, participação, desenvolvimento e aprendizagem de alunos com deficiência, é apresentar uma análise que contribua para os investimentos que o CFP vem fazendo.
O contexto educacional brasileiro tem vivenciado nas últimas três décadas uma reconfiguração política orientada para a efetivação de condições de desenvolvimento e aprendizagem para todos. Nesse contexto, a política de inclusão escolar dos alunos com deficiência, instituída a partir de programas, decretos, portarias e legislações, tem feito investimentos com vistas à efetivação do acesso, participação, desenvolvimento e aprendizagem desses alunos no espaço da escola comum.

A partir disso e entendendo que, na racionalidade da governamentalidade biopolítica, a inclusão escolar das pessoas com deficiência se constitui como estratégia necessária para um bom governo da população (Lopes, 2009), questionamos: como a acessibilidade tem se constituído como condição para o acesso, a participação, o desenvolvimento e a aprendizagem de alunos com deficiência? Para a análise proposta, tomamos três documentos que orientam a política de inclusão a partir dos anos 2000: Lei $\mathrm{n}^{\circ}$ 10.098, de 19 de dezembro de 2000²; Plano Nacional dos Direitos da Pessoa com Deficiência - Viver sem Limite, de 2013 (Brasil, 2013) ${ }^{3}$ e Lei no 13.146, de 6 de julho de $2015^{4}$.

\footnotetext{
${ }^{1}$ A pesquisa tem como objetivo analisar de que modo a inclusão, compreendida como direito e um imperativo de Estado, se constitui como uma estratégia para o governo das chamadas diferenças por meio de processos de subjetivação que se dão a partir da educação.

${ }^{2}$ Esta Lei estabelece as normas gerais e critérios básicos para a promoção da acessibilidade das pessoas portadoras de deficiência ou com mobilidade reduzida e dá outras providências.
} 
Desenvolvemos esta análise a partir da noção de governamentalidade biopolítica de Michel Foucault. A governamentalidade biopolítica investe na potencialização da vida, de modo a fazer com que os sujeitos se tornem úteis, produtivos e aptos às demandas de uma racionalidade econômica neoliberal. Nessa racionalidade, a vida passa a ser uma questão política, e sua gestão é feita de forma calculada, por meio do desenvolvimento de saberes como a estatística, a demografia e a pedagogia, entre outros. A vida dos sujeitos passa a ser escrutinada, analisada, descrita e governada, de maneira que suas condutas sejam gradualmente moldadas às exigências políticas e econômicas.

Diante dessa lógica, a matrícula de todos os alunos com idades entre quatro e 17 anos no sistema educacional e a obrigatória garantia de condições de acesso, participação, desenvolvimento e aprendizagem estão na ordem do discurso educacional brasileiro. A concretização de condições para que todos possam ingressar na escola comum, frequentá-la e nela permanecer e aprender tem se constituído tanto como um direito quanto como um imperativo de Estado que se organiza pelos princípios democráticos em uma lógica econômica neoliberal.

O neoliberalismo, aqui compreendido como um modo de vida e uma racionalidade de governo, institui práticas e determina formas de gestão das condutas para que estas se tornem participativas, autônomas, aprendizes e flexíveis. As "autoridades devem usar seus poderes para melhorar o bem-estar nacional" e atuar "sobre os fins que devem buscar, os males que eles devem evitar, os meios que devem usar e, em especial, a natureza das pessoas sobre as quais elas devem agir" (ROSE, 2011, p. 214).

Compreendendo que essa racionalidade tem se propagado nas políticas e na organização do território escolar nas últimas décadas, apoiada em tecnologias específicas, a política de educação de todos objetiva organizar elementos e características que estejam sintonizadas com as tendências globais de mercado. Ao considerarmos essa condição de vida no presente, organizamos a presente análise em duas seções. Na primeira, discutimos a inclusão escolar das pessoas com deficiência como um imperativo de Estado que se desdobra a partir de uma racionalidade orientada a investimentos que instiguem formas de vida participativas, autônomas, aprendizes e flexíveis. Na segunda, analisamos como, por meio da acessibilidade - entendida como uma estratégia política e econômica potencializadora da inclusão escolar -, o acesso, a participação, o desenvolvimento e a aprendizagem das pessoas com deficiência na escola comum são constituídos por meio de práticas que buscam promover tais condições de forma equânime.

\section{Inclusão como um imperativo de Estado voltado para um bom governo da população}

Frente ao cenário político e econômico brasileiro das últimas três décadas, organizado a partir de uma racionalidade neoliberal, o Estado brasileiro realizou investimentos para que os alunos com deficiência tenham garantidas condições de acesso, participação, desenvolvimento e aprendizagem na "rede da inclusão" (Machado, 2016). Por meio desses investimentos, a acessibilidade tem se configurado como uma estratégia que possibilita a inclusão de todos nos fluxos econômicos. A acessibilidade para as pessoas com deficiência, na política de inclusão escolar, é compreendida como:

Um atributo do ambiente que garante que todos convivam de forma independente, com segurança e autonomia, nos espaços, mobiliários e equipamentos abertos ao público ou de uso público (Brasil, 2013, p. 49).

Possibilidade e condição de alcance para utilização, com segurança e autonomia, de espaços, mobiliários, equipamentos urbanos, edificações, transportes, informação e comunicação, inclusive seus sistemas e tecnologias, bem como de outros serviços e instalações abertos ao público, de uso público ou privado de uso coletivo, tanto na zona urbana como na zona rural, por pessoa com deficiência ou com mobilidade reduzida ( $L e i$ $N^{\circ} 13.146,2015$, Art. 30).

A acessibilidade é direito que garante à pessoa com deficiência ou com mobilidade reduzida viver de forma independente e exercer seus direitos de cidadania e de participação social (Lei $N^{o}$ 13.146, Art. 53º.

${ }^{3}$ O Plano tem a finalidade de promover, por meio da integração e articulação de políticas, programas e ações, o exercício pleno e equitativo dos direitos das pessoas com deficiência, nos termos da Convenção Internacional sobre os Direitos das Pessoas com Deficiência e seu Protocolo Facultativo.

${ }^{4}$ Institui a Lei Brasileira de Inclusão da Pessoa com Deficiência (Estatuto da Pessoa com Deficiência). 
Se, por um lado, a acessibilidade pode ser compreendida como um direito a ser garantido mediante a promoção de condições de acesso e de participação em espaços, práticas e comunicações para todos os sujeitos, por outro, constitui-se como um imperativo de Estado que requer a constituição de um modo de vida adequado às regras do mercado. A acessibilidade, assim, está implicada na constituição de modos de vida que possibilitem a participação das pessoas com deficiência nos fluxos de aprendizagem, desenvolvendo suas potencialidades e competências individuais.

Pelo imperativo da inclusão escolar, investe-se nas condutas dos sujeitos com deficiência por meio de práticas de normalização que modulam as singularidades para se inserirem no jogo da participação permanente. Desse modo, os espaços escolares vêm sendo convocados a:

organizar as condições de acesso aos espaços, aos recursos pedagógicos e à comunicação que favoreçam a promoção da aprendizagem e a valorização das diferenças, de forma a atender às necessidades educacionais de todos os alunos. A acessibilidade deve ser assegurada mediante a eliminação de barreiras arquitetônicas, urbanísticas, na edificação - incluindo instalações, equipamentos e mobiliários - e nos transportes escolares, bem como as barreiras nas comunicações e informações (Brasil, 2008, p.12).

Por meio da legislação que regula - leis, decretos e resoluções - e das políticas que orientam sua implementação, foram instituídos, nas últimas décadas, ações e programas para a efetivação das condições necessárias para a promoção da aprendizagem, a valorização das diferenças e a materialização de processos educacionais inclusivos que têm a acessibilidade como principal pilar. Com isso, as circunstâncias pelas quais as necessidades individuais são atendidas revestem-se de uma leitura da singularidade de cada sujeito, correlacionando essa condição ao espaço escolar que o aluno frequenta. Portanto, a busca pela promoção de condições equânimes para que todos, independentemente das características pessoais, possam ter garantidas possibilidades de acesso, participação, desenvolvimento e aprendizagem requer que os espaços educacionais tenham como premissa o princípio balizador de que:
A educação constitui direito da pessoa com deficiência, assegurados sistema educacional inclusivo em todos os níveis e aprendizado ao longo de toda a vida, de forma a alcançar o máximo de desenvolvimento possível de seus talentos e habilidades físicas, sensoriais, intelectuais e sociais, segundo suas características, interesses e necessidades de aprendizagem (Lei No 13.146, 2015, Art. 27).

Esse direito, pautado na Constituição Federal de 1988 - que coloca a educação como o primeiro dos direitos sociais (Art. $6^{\circ}$ ) -, fundamenta-se também no reconhecimento, em nível internacional, do direito das pessoas com deficiência à educação. Este implica a necessidade de assegurar um "sistema educacional inclusivo em todos os níveis e uma aprendizagem ao longo da vida" (ONU, 2006, Art. 27). No início da década de 1990, o Estatuto da Criança e do Adolescente estabelece como princípio fundamental de toda criança e adolescente o Direito à Educação, Cultura, Esporte e ao Lazer, fixando, enquanto dever do Estado, a oferta de:

Ensino Fundamental, obrigatório e gratuito, inclusive para os que a ele não tiveram acesso na idade própria; progressiva extensão da obrigatoriedade e gratuidade ao ensino médio; atendimento educacional especializado aos portadores de deficiência, preferencialmente na rede regular de ensino; atendimento em creche e pré-escola às crianças de zero a seis anos de idade; acesso aos níveis mais elevados do ensino, da pesquisa e da criação artística, segundo a capacidade de cada um; oferta de ensino noturno regular, adequado às condições do adolescente trabalhador; atendimento no ensino fundamental, através de programas suplementares de material didático-escolar, transporte, alimentação e assistência à saúde (Lei No 8.069, 1990, Art. 54).

No contexto econômico e político do presente, em que as ações desenvolvidas pelo Estado objetivam potencializar as condições de vida de todos, "as pessoas não são (mais) tomadas como cidadãos sociais (cuja liberdade ou autonomia seria garantida pela normalidade social ou por aqueles que teriam uma relação normalizada para consigo), mas entendidas como eus empresariais e empresários de si" (Simons; Maschelein, 
2011, p. 124). Nesse sentido, "o governo de si empresarial implica o olhar para si mesmo como habitante de um ambiente particular, que tem necessidades e que produz bens (ou mesmo investe em capital humano) com o propósito de conhecer e satisfazer essas necessidades" (Idem.). Ao dispor de estratégias que possam ampliar as condições de acesso, participação, desenvolvimento e aprendizagem nos espaços escolares e na sociedade, o enfoque político investe na potencialização das capacidades individuais. No limite, operacionaliza-se com a norma de distintas formas, pois não se trata mais de colocar todos na ordem disciplinar da normação $0^{5}$ prevista na Modernidade, mas é necessário operar pelo dispositivo da normalização, próprio de nosso tempo ${ }^{6}$ (Lopes; Rech, 2013). Assim, preconiza-se a "adoção de medidas individualizadas e coletivas em ambientes que maximizem o desenvolvimento acadêmico e social dos estudantes com deficiência, favorecendo o acesso, a permanência, a participação e a aprendizagem em instituições de ensino" (Lei $N^{o}$ 13.146, 2015, Art. 28, Inciso V).

Com tal enfoque, o Estado tem se organizado principalmente como "conselheiro, coordenando um batalhão de experts e instituições que produzem saberes sobre os riscos e sobre as formas de minimizá-los" (Saraiva, 2013, p. 171). Para isso, em vista da garantia do direito à educação das pessoas com deficiência, dissipa-se o incentivo de projetos pedagógicos que institucionalizem

o atendimento educacional especializado, assim como os demais serviços e adaptações razoáveis, para atender às características dos estudantes com deficiência e garantir seu pleno acesso ao currículo em condições de igualdade, promovendo a conquista e o exercício de sua autonomia. (Lei No 13.146, 2015, Art. 28, Inciso III).

Busca-se, então, uma articulação entre as condições dos espaços e as condições individuais dos alunos com deficiência. Pela política de inclusão escolar efetivada pelas condições de acessibilidade, estima-se que as pessoas com deficiência se constituam como sujeitos aprendizes, flexíveis e participativos. Na ordem discursiva de potencialização da vida de todos, compreendemos que a inclusão escolar de pessoas com deficiência é um movimento que redefine práticas voltadas ao governo da população, principalmente pela gradual minimização dos riscos da exclusão, da segregação, do analfabetismo e da dependência econômica, entre outros. Destacados alguns aspectos que marcam o direito e o imperativo da inclusão escolar de pessoas com deficiência, na próxima seção, buscamos responder a questão que orienta este artigo e que aqui retomamos: como a acessibilidade tem se constituído como condição para o acesso, a participação, o desenvolvimento e a aprendizagem de alunos com deficiência?

\section{Acessibilidade como condição para o acesso, a participação, 0 desenvolvimento e a aprendizagem de alunos com deficiência}

As políticas educacionais enfatizam que "todos devem ser atingidos por um tipo de educação que produza sujeitos que já não dependem de políticas públicas e ações assistencialistas" (Saraiva; Lopes, 2011, p. 29). Esse imperativo encontra potência na escola, que, na contemporaneidade, vem alargando suas funções para atender aos princípios de uma sociedade que se caracteriza como de aprendizagem. Na sociedade de aprendizagem, há um deslocamento de ênfase - do ensino para a aprendizagem -, o que requer sujeitos capazes de aprender a aprender.

Segundo Lockmann (2013), o alargamento das funções da escola e o esmaecimento daquilo que se compreendia como conhecimento escolar "direcionam a condução das condutas dos sujeitos, numa orientação que privilegia suas formas de ser, de se relacionar e de se comportar na sociedade" (p. 166). Em uma sociedade onde a aprendizagem se apresenta como produtiva forma de governamento pedagógico, 0 papel central da Educação tem se instituído pela racionalidade de que todos devem aprender de forma contí-

\footnotetext{
${ }^{5}$ A partir de Michel Foucault, compreendemos a normação como uma prática que visa a conformar as pessoas a partir dos padrões constituídos previamente no próprio grupo, ou seja, pela normação, parte-se da norma para distinguir o normal do anormal. Na normalização, ao contrário da normação, parte-se do "assinalamento do normal e do anormal, um assinalamento das diferentes curvas de anormalidade" (Foucault, 2008, p. 83), que faz com que as diferentes atribuições de normalidade interajam para que as mais desfavoráveis se aproximem das mais favoráveis.

${ }^{6}$ Cabe destacar que, apesar de os processos de normalização contemporâneos "terem multiplicado as normas - pois essas são determinadas a partir da normalidade de cada grupo -, não ficam descartados os processos disciplinares de correção e acompanhamento individual" (Lopes; Rech, 2013, p. 212).
} 
nua, estando sempre dispostos a se modificarem e a se readaptarem (Bauman, 1998; 2001). Essa racionalidade exige que os sujeitos estejam aptos e consigam adaptar-se às mudanças constantes, e, para aqueles com deficiência, são necessárias "medidas de apoio que favoreçam o desenvolvimento dos aspectos linguísticos, culturais, vocacionais e profissionais, levando-se em conta o talento, a criatividade, as habilidades e os interesses do estudante" (Lei No 13.146, 2015, Art. 28, Inciso IX). Logo, aprender várias coisas de forma ativa e articulada torna-se a condição de vida no presente, conforme estudo desenvolvido por Noguera-Ramírez:

Pode-se dizer que a Modernidade [que] se inaugurou nos séculos XVI e XVII como "sociedade do ensino", hoje se estaria fechando sob a forma de uma "sociedade da aprendizagem" e teríamos assim uma grande virada: da ênfase inicial no "ensino" e na "instrução" para a ênfase na "aprendizagem" (2009, p. 230).

Sendo a escola, portanto, o lugar pelo qual todos devem passar, espera-se também que, por meio dela, todos sejam conduzidos à participação nos mais variados espaços sociais, sendo o aprendiz aquele em quem as políticas devem investir como potencial capital humano. Podemos observar isso no documento da Política Nacional de Educação Especial na Perspectiva da Educação Inclusiva, onde lemos que:

As pessoas se modificam continuamente, transformando o contexto no qual se inserem. Esse dinamismo exige uma atuação pedagógica voltada para alterar a situação de exclusão, reforçando a importância dos ambientes heterogêneos para a promoção da aprendizagem de todos os alunos (Brasil, 2008, p. 9).

A educação, pelo viés da inclusão escolar, passa a ser uma estratégia biopolítica que colabora para tornar a vida de cada sujeito - e da população em seu conjunto - produtiva e alinhada com a lógica de participação de todos. Para tal, deve-se conceber o direito à educação de todos como "inalienável e universal, sendo também considerado um direito que viabiliza a realização de outros direitos, pois ele prepara as pessoas com deficiência para o trabalho e para a obtenção de renda que lhes garantam viver com independência e dignidade" (Brasil, 2013, p. 15).
Nesse cenário, as ações que objetivam promover e efetivar o acesso, a participação, o desenvolvimento e a aprendizagem das pessoas com deficiência na escola regular são desenvolvidas por meio de:

- ImplementaçãodeSalasdeRecursosMultifuncionais (SRMs) "equipadas com mobiliários, materiais pedagógicos e de acessibilidade destinados a atender às especificidades educacionais" (Brasil, 2013, p. 13). Segundo dados do Plano, até o ano de 2011, 24 mil escolas brasileiras estavam equipadas com as salas de recursos, abrangendo, assim, um total de $83 \%$ dos municípios do país. Para que até 2014 fossem implantadas mais 15 mil salas, foi prevista a aquisição de 30 mil kits com materiais e equipamentos. A partir desse investimento, também as primeiras salas equipadas com os materiais específicos ao atendimento educacional especializado passaram a ser contempladas com materiais atualizados.

- Programa Escola Acessível, voltado à promoção de condições de acessibilidade ao ambiente físico, aos recursos didáticos e pedagógicos e à comunicação e informação nas escolas públicas do ensino regular. O Programa estabelece a disponibilização de "recursos financeiros às escolas públicas, por meio do programa Dinheiro Direto na Escola, para a promoção da acessibilidade arquitetônica nos prédios escolares e compra de materiais e equipamentos de tecnologia assistiva" (Brasil, 2013, p. 16). O enfoque deste Programa, por meio do Plano Viver sem Limite, estava em garantir que, até o ano de 2014, 42 mil escolas no território nacional tivessem acesso ao recurso para investimento em acessibilidade arquitetônica. Segundo dados do governo federal, "entre 2011 e 2012, 21.288 do total das escolas previstas já haviam sido contempladas" (Brasil, 2013, p. 16).

- Transporte Escolar Acessível - Caminho da Escola, que "prioriza municípios com maior número de beneficiários do $\mathrm{BPC}^{7}$ em idade escolar obrigatória e que estão fora da escola" (Brasil, 2013, p. 18). Essa ação volta-se à aquisição de veículos acessíveis para transportar os alunos com deficiência para a escola e para o atendimento educacional especializado. Objetiva-se, com a distribuição nacional desses veículos, garantir que 60 mil estudantes possam utilizar esse meio de transporte e, assim, gradativamente, participar do contexto escolar. 
- Pronatec, ${ }^{8} \mathrm{com}$ enfoque na formação profissional, visa a ofertar cursos técnicos de nível médio e de formação inicial e continuada em que todas as vagas dispostas podem ser "acessadas por pessoas com deficiência, independentemente do ofertante, do curso e do tipo de deficiência, com atendimento preferencial na ocupação das vagas" (Brasil, 2013, p. 22). O Programa oferece bolsas de formação que objetivam "expandir e democratizar a educação profissional e tecnológica no país" (Brasil, 2013, p. 21).

- Programa Acessibilidade na Educação Superior - Incluir, voltado à criação e reestruturação de Núcleos de Acessibilidade nas instituições federais de ensino superior para "garantir o acesso de estudantes, professores e servidores com deficiência a todos os espaços, ações e processos, buscando seu pleno desenvolvimento acadêmico" (Brasil, 2013, p. 26), por meio de recursos específicos do orçamento da União para a promoção da política de inclusão escolar no ensino superior.

- No que tange aos sujeitos surdos, e para que a educação bilíngue seja uma realidade no sistema educacional brasileiro, por meio dos recursos do Programa Viver sem Limite, foram criados 27 cursos de Letras/Libras na modalidade licenciatura e bacharelado e mais 12 cursos de Pedagogia na perspectiva bilíngue (Brasil, 2013), com previsão de "690 vagas para que as instituições federais de educação contratem professores, tradutores e intérpretes de Libras" (Brasil, 2013, p. 27).

Esses investimentos visam a promover a inclusão das pessoas com deficiência na educação por meio de condições de acessibilidade. Entendemos que a acessibilidade, sozinha, não efetiva a inclusão, mas é um dos pilares condicionadores dessa política e vem sendo condição para que a inclusão aconteça desde a Lei ${ }^{\circ} 10.098$, de 2000 . Se, pela Lei no 10.098 , pretendia-se estabelecer "normas gerais e critérios básicos para a promoção da acessibilidade das pessoas portadoras de deficiência ou com mobilidade reduzida" (Art. 10), passados 15 anos, a Lei no 13.146 estabelece que o Estatuto da Pessoa com Deficiência objetiva "assegurar e [...] promover, em condições de igualdade, o exercício dos direitos e das liberdades fundamentais por pessoa com deficiência, visando a sua inclusão social e cidadania" (Lei No 13.146, 2015, Art. $1^{\circ}$ ), alargando-se o imperativo da acessibilidade como condição para a inclusão.

Situar a inclusão escolar pela via da acessibilidade possibilita uma chave de leitura que a coloca como produtiva estratégia de condução dos sujeitos à participação, possibilitando a todos que adentrem no jogo do mercado, sendo flexíveis e aptos a atender às demandas de uma racionalidade econômica neoliberal. A lógica de governo que se constitui aqui segue o que Foucault considerou como "governar mais com menos governo" (2008) e visa à colaboração de todos para o desenvolvimento da economia do país. Essa dinâmica econômica não deve ser entendida como ajustamento a modelos econômicos, mas como um governamento das formas de vida que objetiva controlar a multiplicidade de sujeitos que constituem a população. Deve ser entendida como uma dinâmica que tem como objetivo garantir/potencializar a vida, como uma economia biopolítica da existência.

Assim, "as políticas de inclusão articulam-se com a regulamentação da vida dos sujeitos aí implicados, na medida em que vão tentar controlar e, se necessário, modificar a probabilidade, a série de acontecimentos da massa viva que é a população" (Sardagna, 2013, p. 56). O investimento operado sobre esses sujeitos objetiva criar condições para que todos possam "estar perto" de uma determinada normalidade e, dessa forma, também alcançar o máximo de desenvolvimento possível de suas habilidades e/ou competências.

A partir da política de inclusão, a diversidade apresenta-se como um elemento para o convívio social e para os processos de ensino e de aprendizagem. Os sujeitos tornam-se fontes de investimento do Estado para que, além de produtores, sejam também consumidores dos mais variados produtos: da informação, das inovações tecnológicas, das ideias e do mercado cultural, entre outros. O modo pelo qual a vida contemporânea tem se delineado configura a necessidade de um sujeito "aprendente por toda a vida que pode recriar continuamente o seu eu ao se tornar um agente de resolução de problemas; um sujeito que seja responsável pelo progresso social e pela realização pessoal de sua própria vida" (Santos; Klaus, 2013, p. 64).

\footnotetext{
${ }^{7}$ Benefício de Prestação Continuada da Assistência Social. Para mais informações, ver: http://www.pessoacomdeficiencia.sp.gov.br/
} beneficio-bpc.

${ }^{8}$ Programa Nacional de Acesso ao Ensino Técnico e Emprego. 
Portanto, muito mais que efetivar acesso, participação, desenvolvimento e aprendizagem, a legislação brasileira está voltada a garantir a "equiparação de oportunidades para que a deficiência não seja utilizada como impedimento à realização de sonhos, desejos, projetos, valorizando o protagonismo e as escolhas dos brasileiros com e sem deficiência" (Brasil, 2013, p. 8). Com isso, a educação escolarizada deve produzir permanentemente no sujeito o desejo da aprendizagem, tendo em vista que o conceito de educação ao longo da vida aparece "como uma das chaves de acesso ao século XXI” (Dellors, 1999, p. 12). Na operacionalização de estratégias para a condução de sujeitos aptos a enfrentar os desafios de nosso tempo, a educação tem sido compreendida como mola propulsora para o desenvolvimento social, econômico e potencial de cada um e de todos, pois a educação

[...] situa-se, mais do que nunca, no âmago do desenvolvimento da pessoa e das comunidades; sua missão consiste em permitir que todos, sem exceção, façam frutificar seus talentos e suas potencialidades criativas, o que implica, por parte de cada um, a capacidade de assumir a sua própria responsabilidade e de realizar seu projeto pessoal (Dellors, 1999, p. 10).

Nesse contexto, a educação ao longo da vida apresenta-se como algo inquestionável que "procura, primordialmente, encaixar as gerações na sociedade em que ela está operando - uma educação que existe para adaptar, acomodar" (Camozzato, 2012, p. 134).
Nas demandas deste novo século, objetiva-se, por meio dos investimentos educacionais, que todos possam "incrementar a capacidade de autonomia e de discernimento, acompanhada pela consolidação da responsabilidade pessoal na realização de um destino coletivo" (Dellors, 1999, p. 14). Nesse sentido, para conduzir, orientar, guiar os sujeitos, torna-se fator crucial investir nas condições de acesso, participação, desenvolvimento e aprendizagem e, desse modo, constituir um conjunto populacional formado por sujeitos que têm suas condutas moduladas para serem participativos, autônomos, flexíveis e aprendizes (Kraemer, 2017).

Entendemos que a governamentalidade biopolítica na qual se inscreve a inclusão escolar tem na acessibilidade sua principal estratégia para efetivar uma política econômica e social que conte com a participação de todos, ainda que isso não capture a todos.

Sem a pretensão de esgotar a discussão, encerramos reiterando que a participação de todos é necessária para um bom governo da população. Os documentos analisados mostram que o Estado, para efetivar a inclusão de todos, investe na promoção de condições de acessibilidade para aqueles classificados como "pessoas com deficiência". Nesse sentido, ao longo do artigo, buscamos mostrar como, em nossos dias, a acessibilidade tem se constituído como condição para a política de inclusão escolar mediante ações que visam a efetivar o acesso, a participação, o desenvolvimento e a aprendizagem e a constituir pessoas com deficiência como sujeitos capazes de aprender e de tornar-se aptos a conduzir-se de forma autônoma, flexível e participativa.

\section{Referências}

Bauman, Z. (2001). Modernidade líquida. Rio de Janeiro, RJ: Zahar.

Bauman, Z. (1998). O mal-estar da pós-modernidade. Rio de Janeiro, RJ: Jorge Zahar.

Brasil. (2013). Viver sem limite: Plano Nacional dos Direitos da Pessoa com Deficiência. Brasília, DF, 2013.

Brasil. (2008). Ministério da Educação. Política Nacional de Educação Especial na perspectiva da educação inclusiva. Brasília, DF: o autor.

Camozzato, V. (2012). Da pedagogia às pedagogias: Formas, ênfases e transformações (Tese). Universidade Federal do Rio Grande do Sul, Porto Alegre, RS.

Dellors, J. (1999). Educação: um tesouro a descobrir: relatório para a Unesco da Comissão Internacional sobre Educação para o Século XXI. São Paulo, SP: Cortez.

Foucault, M. (2008). Segurança, território, população: Ccurso ministrado no Collège de France (1977-1978). São Paulo, SP: Martins Fontes.

Kraemer, G. M. (2017). A modulação das condutas das pessoas com deficiência no direito à escola comum brasileira (Tese). Universidade Federal do Rio Grande do Sul, Porto Alegre, RS. 
Lei No 8.069, de 13 de julho de 1990. Dispõe sobre o Estatuto da Criança e do Adolescente e dá outras providências. Diário Oficial da União, 16 jul. 1990.

Lei $N^{o} 10.098$, de 19 de dezembro de 2000. Estabelece normas gerais e critérios básicos para a promoção da acessibilidade das pessoas portadoras de deficiência ou com mobilidade reduzida, e dá outras providências. Diário Oficial da União, 20 dez. 2000.

Lei No 13.146, de 6 de julho de 2015. Institui a Lei Brasileira de Inclusão da Pessoa com Deficiência. (Estatuto da Pessoa com Deficiência). Diário Oficial da União, 7 jul. 2015.

Lockmann, K. (2013). A proliferação de políticas de assistência social na educação escolarizada: estratégias da governamentalidade neoliberal. (Tese). Universidade Federal do Rio Grande do Sul, Porto Alegre, RS

Lopes, M. C. (2009). Políticas de inclusão e governamentalidade. Educação \& Realidade, 34(2), 153-169.

Lopes, M. C., \& Rech, T. L. (2013). Inclusão, biopolítica e Educação. Educação (Porto Alegre), 36(2), 210-219.

Machado, R. B. (2016). A inclusão como rede: uma análise de práticas de professores de educação física na contemporaneidade (tese). 2016Universidade Federal do Rio Grande do Sul , Porto Alegre, RS.

Noguera-Ramírez, C. E. (2009). O Governamento Pedagógico: Da sociedade de ensino para a sociedade de aprendizagem (Tese). Universidade Federal do Rio Grande do Sul, Porto Alegre, RS

Organização das Nações Unidas - ONU. (2006). Convenção sobre os direitos das pessoas com deficiência. New York: o autor.

Rose, N. (2011). Inventando nossos selfs: Psicologia, poder, subjetividade. Petrópolis, RJ: Vozes.

Santos, I. M., Klaus, V. (2013). A inclusão do sujeito empresário de si. In: E. T. H. Fabris, \& R. R. Klein (Orgs.), Inclusão e biopolítica (pp. 61-78). Belo Horizonte, MG: Autêntica.

Saraiva, K. (2013). Educando para viver sem riscos. Educação (Porto Alegre), 36(2), 168-179.

Saraiva, K., \& Lopes, M. C. (2011). Educação, inclusão e reclusão. Currículo sem Fronteiras, 11(1), 14-33.

Sardagna, H. V. (2013). Da institucionalização do anormal à inclusão escolar. In: E. T. H. Fabris, \& R. R. Klein (Orgs.), Inclusão e biopolítica (pp. 45-60). Belo Horizonte, MG: Autêntica.

Simons, M.; Masschelein, J. (2011). Sociedade da aprendizagem e governamentalidade: Uma introdução. Currículo Sem Fronteiras, 11(1), 121-136.

Thoma, A. S. (2016). Inclusão, subjetivação e governo das diferenças na educação. Projeto de Pesquisa aprovado pela COMPESQ EDU e PROPESQ UFRGS. Universidade Federal do Rio Grande do Sul, Porto Alegre, RS.

\section{Graciele Marjana Kraemer}

Graduada em Educação Especial - Deficientes da Audiocomunicação pela Universidade Federal de Santa Maria (UFSM). Mestre e doutora em Educação pela Universidade Federal do Rio Grande do Sul (UFRGS). Em Estágio de Pós-doutorado no Programa de Pós-Graduação em Educação Unisinos.

E-mail: graciele.kraemer@gmail.com

\section{Adriana da Silva Thoma}

Graduada em Educação Especial pela Universidade Federal de Santa Maria (UFSM). Mestre e doutora em Educação pela Universidade Federal do Rio Grande do Sul (UFRGS). Pós-doutora pela Universidade de Santa Cruz do Sul. Professora Associada I da UFRGS, atuando no Departamento de Estudos Especializados da Faculdade de Educação e no Programa de Pós-Graduação em Educação.

E-mail: asthoma@terra.com.br

Endereço para envio de correspondência:

UFRGS / FACED / PPGEdu

Av. Paulo Gama, s/nº prédio 12.201, $8^{\circ}$ andar, sala 805

90046-900 - Porto Alegre/RS 
Recebido: 29/06/2018

Aprovado: 03/07/2018

Received:06/29/2018

Approved: 07/03/2018

Recibido: 29/06/2018

Aceptado: 03/07/2018

Como citar: Kraemer, G. M., \& Thoma, A. S. (2018). Acessibilidade como condição de acesso, participação, desenvolvimento e aprendizagem de alunos com deficiência. Psicologia: Ciência e Profissão, 38(3), 554-563. https://doi.org/10.1590/1982-3703000062018

How to cite: Kraemer, G. M., \& Thoma, A. S. (2018). Accessibility as a condition for access, participation, development and learning of students with disabilities. Psicologia: Ciência e Profissão, 38(3), 554-563. https://doi.org/10.1590/1982-3703000062018

Cómo citar: Kraemer, G. M., \& Thoma, A. S. (2018). Accesibilidad como condición de acceso, participación, desarrollo y aprendizaje de alumnos com discapacidad. Psicologia: Ciência e Profissão, 38(3), 554-563. https://doi.org/10.1590/1982-3703000062018 